\title{
Operationalizing the Concept of Neighborhood: Application to Residential Location Choice Analysis
}

\author{
Jessica Y. Guo* and Chandra R. Bhat \\ Department of Civil Engineering, University of Texas at Austin, 1 University Station C1761, \\ Austin, TX 78712-0278, USA \\ Email: jessica.guo@mail.utexas.edu,bhat@mail.utexas.edu
}

Phone: 512-471-4535, Fax: 512-475-8744

* Corresponding author

\begin{abstract}
In this paper, we explore different conceptualizations to represent neighborhoods in residential location choice models, and describe three alternative ways for constructing operational units to represent neighborhoods. In particular, we examine the possibility of using the census units to represent the hierarchical 'fixed neighborhood' definition, and the circular units and network bands to represent the hierarchical 'sliding neighborhood' definition. Overall, the network band definition is conceptually appealing. It also is marginally superior to the other two operational representations from a model fit standpoint.
\end{abstract}

Keywords: Neighborhood; Spatial definition; Residential location choice; Modifiable areal unit problem 


\section{Introduction}

In the literature relating to urban planning and travel behavior modeling, 'neighborhood' is a widely used and important term. Studies of the housing market investigate what kind of people live in what kind of neighborhoods (Hunt et al., 1994). Research work on the landuse/transportation interaction frequently use neighborhood as a synonym for built environment or land-use. In particular, advocates and skeptics of the 'New Urbanism' concept talk about whether neighborhood design and other characteristics can affect various aspects of travel behavior (Ewing and Cervero, 2001).

Obviously, any study about neighborhoods is a spatial investigation. Yet, the spatial definition of neighborhood has received very little attention in the literature. Theoretical studies of neighborhood effects often use the term neighborhood rather loosely. For instance, New Urbanism designs tend to focus on the micro scale of four hundred meters (one-quarter mile) or less. Yet it is not clear on an a priori basis whether residential and travel choice behavior is influenced by the urban form within small neighborhoods, or over larger areas, or both. On the other hand, empirical studies of neighborhood effects across many disciplines typically use census tracts, zip code areas, or transport analysis zones (TAZ) as operational surrogates for neighborhoods (Sampson et al., 2002; Dietz, 2002). This use of administrative boundaries as operational units typically has little theoretical foundation and subjects the analysis to the modifiable areal unit problem (MAUP) (Openshaw, 1984), leading to potentially inaccurate analytic outcomes and erroneous recommendations for urban policy (see, for example, Fotheringham and Wong, 1991, and Guo and Bhat, 2004, for more detailed discussions of the MAUP). 
So how do we define neighborhoods? Or, how do we measure neighborhood characteristics and the associated effects? Our simple answer is that we should measure what matters to people over the area that really matters to people. For example, in the study of residential location choice, a common hypothesis is that good access to stores is an attractive neighborhood feature. When examining such a hypothesis, if we define a neighborhood over too large an area, any spatially concentrated commercial activities would likely be averaged out with surrounding low-density patterns. Consequently, it would be difficult to associate the commercial intensity with the choice behavior being studied. Alternatively, if we arbitrarily define a neighborhood to exclude a commercial center that is in fact easily accessible for a given household, it would again be difficult to account for the presence of the commercial center in explaining the residential location choice of that household. Therefore, only when the chosen definition reflects the decision makers' perceived neighborhoods can we accurately study the effect of neighborhoods.

The objective of this paper is to clarify what we, as decision makers and as analysts, mean by neighborhood and to develop ways of operationalizing the concept of neighborhood. With residential location choice as the application context, we expand on an earlier work (Guo and Bhat, 2004) that proposed a hierarchical spatial representation of neighborhoods to examine neighborhood effects. Our previous study showed the superiority of the hierarchical, multi-scale, approach over the conventional, single-scale, approach to accommodate the effect of built form, land use, and other neighborhood attributes. However, the challenge remains regarding how to exploit the flexibility of using analyst-defined spatial units to appropriately identify the impacts of neighborhood factors. In this paper, we specifically examine three alternative sets of operational units for neighborhood definition and embed these spatial representations to study 
the effects of neighborhood factors on households' residential location choices. Our results demonstrate the feasibility of using these operational units of neighborhood, the sensitivity of modeling outcomes to the choice of spatial units, and the strengths and limitations of the alternative units.

The remainder of this paper is structured as follows. The next section discusses the concept of neighborhood, as used in earilier studies. Section 3 provides a background for residential location choice analysis and discusses the methodological shortcomings in the conventional approach with regard to the definition of neighborhood. Section 4 briefly reviews the hierarchical approach proposed in Guo and Bhat (2004) for representing neighborhoods in residential location choice analysis. Section 5 discusses three different ways to operationalize the concept of hierarchical neighborhoods. An empirical application of the three ways of representing neighborhoods is described in Section 6. Finally, Section 7 concludes with a summary of the contribution of the study.

\section{Concept of Neighborhood}

Urban social scientists have treated 'neighborhood' in much the same way as courts of law have treated pornography: a term that is hard to define precisely, but everyone knows it when they see it. (Galster, 2001, p.2111)

Indeed, 'neighborhood' is a vague, difficult-to-define, concept. Scholars investigating the significance of neighborhood for individuals' behavior and well-being often do not provide the term with an explicit definition. When spatial definition of neighborhood is required for the purpose of quantitative analysis, "most social scientists and virtually all studies of neighborhoods ... rely on geographic boundaries defined by the Census Bureau or other administrative agencies... [which] offer imperfect operational definitions of neighborhoods for research and 
policy" (Sampson et al., 2002, p.445). This widespread practice suggests that perhaps we don't really know 'it' - at least not as well as we think - when we see 'it'. To better understand the nature of neighborhood, we review and discuss below a collection of approaches for defining the term. The review is by no means exhaustive, as our focus is on definitions that will bring us closer to formulate operational units for neighborhoods. The reader is referred to Galster (2001) for a more extensive survey of the literature.

An area in which neighborhood definition plays an important role is the study of neighborhood effects, which refers to the neighborhood influences on the well-being and behavior of families, and often children in particular. A pioneering study (Park, 1916) in the field points out that cities are generally outlined by their physical geography, natural advantages, and transportation systems. The processes of human nature then proceed to shape cities through competitive forces for efficient locations among businesses and individuals. These informal processes result in the formation of neighborhoods - naturally segregated localities that share similar sentiments, traditions and history. Followers of this line of thought tend to consider neighborhoods as discrete, non-overlapping, communities, leading to the common use of administratively defined zones for analyzing neighborhood effects.

Later, Suttles (1972) argues that, in addition to being the result of free-market competition, some communities' identities and boundaries are imposed by outsiders. Suttles also suggests that neighborhoods are best thought of not as distinct areas of a city, but rather as a hierarchy of ecological grouping at four levels. At the lowest level is the 'local networks and the face-block', namely, a grouping of residents who share the same local facilities and residential condition because of their proximity to each other. A neighborhood, defined at this level, is usually different for each person and is unlikely to have any sharp boundaries. The second level 
is labeled the 'defending neighborhood', defined as "the smallest area which possesses a corporate identity known to both its members and outsiders". Its size may vary, but it is generally large enough to include a complement of establishments (grocery, liquor store, church, etc.) that people use in their daily round of local movements. The next level, the 'community of limited liability', is typically a construct imposed by external commercial and governmental interests. Residents may be associated with multiple communities whose boundaries are fragmented and overlapping. The highest level in the neighborhood hierarchy is the "expanded community of limited liability'. These are large scale community organizations referring to entire sectors of a city, such as North Austin, whose identity usually arises from government policies and programs.

Galster (2001) defines a neighborhood as a 'complex commodity' that is produced by the same actors - households, businesses, property owners and local governments - that consume them. Neighborhood is a bundle of spatially based attributes, including structural, infrastructural, demographic, class status, tax/public service package, environmental, proximity, political, social-interactive, and sentimental characteristics. Consistent with Suttle's (1972) multi-scale view of neighborhood, Galster argues that the geographical scale across which a neighborhood attribute varies is often different for different attributes. Consumers' perceived delineation of a neighborhood thus depends on the particular neighborhood attributes of interest. This view is also shared by O'Campo (2003), who contends that the processes operating in the neighborhood environment are often many and that the ideal geographic units of analysis for different social processes may not be compatible.

The multi-scale structure of neighborhood can also be viewed as residents having multiple neighborhood memberships. As different processes (social, educational or religious) 
unfold, a household can identify its local identity through its residential neighbors, the school the children go to, its membership in a church, etc. These group memberships lead to spatial clusters, some of which may be objectively recognizable (such as a school catchment area or a gated community). In other cases, however, there are often no clear cutoff points for determining how far social contact or other processes reach. The boundaries for such neighborhood attributes are subjective and fuzzy. As group memberships of individuals evolve with their changing roles in the network of social interaction and their stage in life cycle, their perceptions of neighborhood also change (Horton and Reynolds, 1971). The perception may also be influenced by race (Lee et al., 1991) and gender (Guest and Lee, 1984). Furthermore, an individual's perceived neighborhood also depends on where she or he lives: "an individual living on the boundary of a census tract probably has more in common with residents of the adjoining tract than with residents on the far side of his own" (Dubin, 1992, p.435). The concept that no set of fixed neighborhood boundaries can accurately describe an urban area is referred to as 'sliding neighborhoods'.

Motivated by the uncertainty about how to construct operational units for neighborhoods in view of the many factors influencing residents' perception, Coulton et al. (2001) examine the residents' perception through their mental maps. They asked 140 parents of minor children to draw a map of what they considered as the boundaries of their neighborhoods. The study found evident discrepancies between resident-defined neighborhoods and census geography. The study also demonstrated that individuals residing in close proximity and homogenous on race, age and gender can differ markedly from one another in how they define the physical space of their neighborhood. This variability renders the task of defining resident-perceived neighborhoods a very challenging proposition. Coulton et al. conclude by suggesting further research on mental 
maps of neighborhoods. However, even residents' hand drawn mental maps, which may be influenced by neighborhood names or generally acknowledged definitions, may not reflect the geographic areas that truly affect them (Shinn and Toohey, 2003).

Grannis $(1998,2003)$ also attempts to construct practical representations of neighborhoods. He contends that street networks are one of the primary tools populations use to organize themselves in urban settings and that "the network of tertiary [small, residential-type] streets give rise to a network of neighborly relations" (Grannis, 1998) (p.1560). In a subsequent effort, Grannis (2003) models cities as multiple independent 'islands' - discontinuous networks of pedestrian streets that are separated by major thoroughfares. By comparing these islands with residents' cognitive maps of their neighborhood, he shows that, while islands circumscribe residents' perception of their neighborhoods, residents typically perceive only a portion of their island as their neighborhood. Like Coulton et al. (2001), he is unable to construct operational spatial units as close proxies for perceived neighborhoods.

The studies discussed above reflect the well-recognized difficulty in defining a neighborhood, both at the conceptual and the operational levels. While the question of neighborhood definition remains to be further explored, the existing literature provides a few pointers for constructing neighborhood boundaries. First, a neighborhood has a geographical reference, but its meaning depends on function and domain. The relevant units depend on the specific process, or the outcome of the process, being studied. Thus, the conventional practice of using a single definition of spatial units to analyze multiple neighborhood processes (such as the effects of various neighborhood factors on residential location choice) may lead to spurious conclusions. Second, an urban region can be viewed as a mix of fixed (objectively recognizable boundaries such as major roads, geographical barriers and political demarcations) and sliding 
(subjective boundaries that depend on the characteristics and location of the residents)

neighborhoods. Certain neighborhood processes are related to fixed boundary definitions, while others are associated with sliding definitions. Third, administratively defined units do not represent real neighborhoods and thus constitute imperfect operational definitions of neighborhoods for research and policy. However, census geography in terms of tracts, block groups and blocks are reasonably consistent with the notion of neighborhood as a nested ecological structure, where different processes take place at different levels of the structure.

\section{Residential Location Choice}

The home is where people typically spend most of their time, a common venue for social contact and, for most people, a major financial and personal investment. One's choice of residence also reflects one's choice of the surrounding neighborhood, which has a significant impact on one's well-being and quality of life. The concept of neighborhood and its definition are, therefore, central to residential location choice analysis.

Residential location choice has long been a multidisciplinary research topic. For urban and transportation planning, the interest in the causes and consequences of individuals' choice of residence arises from the recognition that it is the values, decisions, and actions of the people who are attracted to certain types of land use patterns that ultimately shape the transportation, land-use, and urban form. The decision of residential location not only determines the connection between the household with the rest of the urban environment, but also influences the household's activity time budgets and perceived well being. Altering land use characteristics by itself might not affect the residents' travel behavior, as expected by proponents of New Urbanism. Rather, travel characteristics might only change after new residents are attracted by new land use and move into an area, while old residents who find the land use unsuitable 
eventually move out (Kitamura et al., 1997; Lund, 2003; Bhat and Guo, 2005). Hence, understanding the why, who, and where questions associated with residential choices is important for devising effective spatial policies to manage travel demand.

Over the past four decades, there has been considerable development in the mathematical modeling of residential activities. A popular modeling approach is based on the discrete choice formulation pioneered by McFadden (1978). Such a formulation is appealing for residential choice analysis for at least the following two reasons: First, the decision on residential location is one that encompasses housing choices as well as the physical and social attributes of the neighborhood. Based on microeconomic random utility theory, the discrete choice approach provides a way of understanding how residents trade-off among the wide range of choice factors that come into play. Second, the discrete choice approach allows the sensitivity to choice attributes to vary across socio-demographic segments of the population through the inclusion of interaction terms of spatial characteristics with demographic characteristics of households. The modeling results can thus help devise urban policies that effectively target specific population groups.

Of the past discrete choice modeling efforts of residential location, most adopt Lerman's (1976) grouped alternatives choice (GAC) model (e.g. Quigley,1985; Gabriel and Rosenthal, 1989; Waddell, 1993 and 1996; Rapaport, 1997; Levine, 1998; Nechyba and Strauss, 1998; Chattopadhyay, 2000; Sermons and Koppelman, 2001; and Deng, Ross, and Wachter, 2003). The GAC model is essentially a multinomial logit (MNL) model where the choice alternatives are the spatial groupings of dwellings, as opposed to the individual dwellings. The probability $P_{n, c}$ that decision maker $n$ chooses a dwelling in grouping $c$ by is given by: 


$$
P_{n, c}=\frac{e^{U_{n, c}}}{\sum_{b=1}^{C} e^{U_{n, b}}},
$$

where $U_{n, c}$ is the utility that decision maker $n$ obtains from grouping $c$ :

$$
U_{n, c}=\beta^{\prime} X_{n, c}+\left(1-\sigma_{c}\right) \ln J_{c} .
$$

In the above equation, $X_{n, c}$ is a vector of observed grouping-specific attributes; $\beta$ is a vector of the model parameters to be estimated; and $J_{c}$ is used to correct for the grouping process so that, other conditions being equal, a large grouping would have a higher probability of being selected than a small grouping. In almost all of the past residential location choice analyses that have adopted the GAC model, the spatial groupings are interpreted as alternative neighborhoods of residence and are conceived as commodities with fixed, clearly defined, boundaries based on administratively defined units such as census tracts (e.g. Lerman, 1975; Sermons and Koppelman, 2001), school districts (Nechyba and Strauss, 1998), or TAZs (Waddell, 1996; Deng, Ross, and Wachter, 2003). The neighborhood characteristics $X_{n, c}$ are then constructed accordingly. Such constructs are assumed to provide an accurate representation of the perceived neighborhood of relevance during the household's decision making process.

The GAC modeling approach has a number of limitations. First, by examining neighborhood attributes over a single definitional configuration of zones, one in fact assumes that every neighborhood factor operates at one and the same spatial scale. The multi-scale nature of neighborhood, as discussed in the preceding section, casts serious doubts on the validity of such an assumption. Second, the use of mutually exclusive administrative zones is a 'fixed neighborhoods' representation, excluding the consideration of the 'sliding neighborhoods' concept. Third, the model parameters $\beta$ are typically interpreted as the effects of the 
neighborhood attributes on location choice. Yet, as a manifestation of the MAUP, parameter estimates may differ when different zonal configurations are used. Hence, unless the zones are coterminous with neighborhoods as perceived by residents, model estimates derived from arbitrarily defined zones should be interpreted only with respect to these zones and may not correctly reflect the residents' choice behavior. This highlights the need to address the limitations of the GAC approach and to seek more accurate ways of representing residential neighborhoods in models of residential location choice.

\section{The Multi-Scale Logit Model}

The use of the GAC model to approximate the ideal disaggregate models (where every distinguishable dwelling is treated as a distinct choice entity) was a result of the lack of detailed data for modeling purposes (Lerman, 1976). The same data constraint has also in part contributed to the use of administrative boundaries as proxy spatial separations for neighborhood definitions. However, the growing availability of rich, micro-level spatial data and the proliferation of geographical information systems (GIS) makes it possible to conceive the MultiScale Logit (MSL) model (Guo and Bhat, 2004) as an alternative approach for modeling residential location choices.

The basic idea of the MSL model is to use multiple definitions of neighborhood within the same study ${ }^{1}$. This solution has been implemented in, for example, hierarchical linear models for studying community psychology (Brodsky, 1999; Duncan et al., 2003), housing price (Orford, 2002) and, to a limited extent, urban form effect on travel behavior (Boarnet and

\footnotetext{
${ }^{1}$ The MSL model can be considered as a spatial application of the multilevel modeling approach (Goldstein, 1995) where factors from multiple geographical scales (representing a hierarchical structure of neighborhoods) are considered in the same analysis.
} 
Sarmiento, 1998). To the best of our knowledge, the MSL model of Guo and Bhat (2004) represents the first implementation of the multi-scale concept of neighborhood in a discrete choice modeling framework.

The MSL model considers each available dwelling unit as a choice alternative. The geographic location of an alternative $i$ is described by a hierarchy of spatial units $S_{i}$. Let $X_{s}^{n, i}$ denote the vector of location attributes observed over a spatial unit $s\left(s \in S_{i}\right)$ for household $n$ of alternative $i$. The utility experienced by household $n$ from choosing dwelling unit $i$ is formally defined as:

$$
U^{n, i}=\sum_{s \in S_{i}} \beta_{s}^{\prime} X_{s}^{n, i}+\sum_{s \in S_{i}} \varepsilon_{s}^{n, i}
$$

The error terms, $\varepsilon_{s}^{n, i}$, represent any unobserved effects at each spatial scale. By assuming that the error terms between different spatial scales are independent of each other, we collapse all the error terms into one and rewrite the above equation as:

$$
U^{n, i}=\sum_{s \in S_{i}} \beta_{s}^{\prime} X_{s}^{n, i}+\varepsilon^{n, i}
$$

Furthermore, the error terms are assumed to be independent across alternatives $i$ to allow the estimation of the $\beta$ parameters using a MNL structure. Relaxing the independence assumptions across spatial scales and/or alternatives is an important research avenue for future research ${ }^{2}$.

The MSL model can be considered as a generalization of Lerman's GAC model by allowing the neighborhood variables measured over more than one spatial scale to enter the utility function. The MSL model structure thus provides a more realistic representation of how

\footnotetext{
${ }^{2}$ If the spatial hierarchical structure follows a fixed-neighborhood definition, then the assumption of independence across alternatives can be accommodated within the general framework of multi-level models by allowing correlations across error terms at each spatial level (see, for example, Goldstein, 1995; Hox and Kreft, 1994).
} 
neighborhoods are perceived as a hierarchy of ecological structures. Moreover, it allows the scale, or scales, at which each neighborhood factor operates to be determined endogenously. That is, the model estimation process reveals not only the neighborhood determinants of significance to the choice behavior but also the spatial extent of their influence. By interpreting the parameters with reference to the spatial scale at which they are statistically significant, we gain insights about the spatial strengths, or cluster sizes, of various neighborhood processes. The empirical results reported in Guo and Bhat (2004) suggest that the MSL approach yields statistically superior models than the GAC approach. The analysis was based on spatial variables measured using census units, thus representing a fixed neighborhood representation. The findings supported the notion that households of different characteristics have different spatial cognitions of their neighborhood boundaries. The MSL modeling approach was found to successfully exploit the modifiability of areal units of measurement to produce richer and more reliable results.

The other advantage of the MSL model over the GAC model is the capability of allowing more flexible representations of neighborhoods. This capability is achieved through configuring the spatial hierarchy, $S_{i}$, to represent different hypothetical delineations of neighborhoods based on the concepts discussed in section 2 . For example, $S_{i}$ can be specified as operational units representing a hierarchy of 'fixed neighborhoods', 'sliding neighborhoods', or a mix of both. However, following this flexibility in neighborhood representation are the questions of how to appropriately implement the different concepts of neighborhoods and how to determine the 'best' implementation for the application at hand. The remainder of this paper represents our first steps in answering these questions. 


\section{Neighborhood Representations}

As discussed earlier, the MSL model structure promotes the use of a hierarchy of spatial units to capture the effects of neighborhood variables. In this section, we consider three alternative ways of operationalizing some of the ideas discussed in section 2 to produce spatial units that can be used in a MSL model to represent residential neighborhoods. Below, we describe each of these three ways and also discuss their respective merits and drawbacks.

\subsection{Census-unit Representation}

Since the census data is often the main source of data about the spatial distribution of sociodemographic variables, one convenient way is to define $S_{i}$ based on the census geography such that $S_{i}=\left\{\right.$ parcel $_{i}$, block $_{i},{\left.\text { block - } \text { group }_{i}, \text { tract }_{i}\right\} \text {, where parcel }}_{i}$ indicates the land parcel on which dwelling $i$ is located, and block $_{i}$, block - group $_{i}$, and tract ${ }_{i}$ are the census block, block-group, and tract that contain dwelling $i$, respectively. Figure 1(a) illustrates an example of the censusbased neighborhood representation for a dwelling.

The census-based definition of $S_{i}$ is a case of 'fixed neighborhood' representation. The spatial delineations represent objectively defined neighborhood boundaries and, by definition, the boundaries at each level of the hierarchy are non-overlapping. Since the boundaries of census units usually follow geographical barriers, streets, and administrative demarcations, the census-unit representation of neighborhoods is suitable when, and only when, the neighborhood process being studied is confined to these boundaries. This could be a very restrictive condition, especially if the analysis is conducted at the relatively micro-scale of census blocks. For example, if the average property value is computed for a given census block to capture the market potential of a dwelling unit in that block, then one in fact assumes that the value of any 
properties in an adjacent block - which could be right across the street from the dwelling unit of interest - is irrelevant to the analysis. Another drawback of using the census-based representation is that census units can vary significantly across space in size and shape. For example, it is highly unlikely that an individual who happens to reside within a census block of $100 \mathrm{~km}^{2}$ would consider the entire block as his/her immediate neighborhood.

\subsection{Circular-unit Representation}

The use of circles to represent an individual's perceived neighborhood is motivated by the concept of 'sliding neighborhoods', where the neighborhood boundaries are subjectively defined by the residents of a dwelling unit. Here, the hierarchy of spatial units is defined as $S_{i}=\left\{\right.$ parcel $\left._{i}, \mathrm{c}_{i}^{1}, \ldots, \mathrm{c}_{i}^{k}\right\}$, where $\mathrm{c}_{i}^{1}, \mathrm{c}_{i}^{2}, \ldots, \mathrm{c}_{i}^{k}$ are circular areas of varying radii $\mathrm{r}_{i}^{1}, \mathrm{r}_{i}^{2}, \ldots, \mathrm{r}_{i}^{k}$ demarcated around and centered about each alternative dwelling. The radii of the circular units may in theory vary for different dwelling units to allow for spatial heterogeneity in perceived neighborhood extents.

Figure 1(b) shows the circular-unit representation of neighborhoods for the same dwelling considered in Figure 1(a). The circular representation is a simple, but naïve way of implementing the sliding neighborhoods concept. It implies that the surrounding environment within a given distance in all directions is equally important to the decision making process. Therefore, the circular-unit representation is suitable only if the neighborhood process under investigation is not confined to natural or artificial barriers that are present within the circular area.

\subsection{Network-band Representation}

A more sophisticated way of representing sliding neighborhoods is to take into account the street network configuration. As suggested by Grannis $(1998,2003)$ and discussed in section 2 of this 
paper, residents' cognitive maps of their neighborhood are at least partially guided by the (connectivity of) street network in the vicinity of their residence. To implement this idea, we define $S_{i}=\left\{\right.$ parcel $\left._{\mathrm{i}}, \mathrm{b}_{i}^{1}, \ldots, \mathrm{b}_{i}^{k}\right\}$, where $\mathrm{b}_{i}^{1}, \mathrm{~b}_{i}^{2}, \ldots, \mathrm{b}_{i}^{k}$ are network bands constructed for varying distances $\mathrm{d}_{i}^{1}, \mathrm{~d}_{i}^{2}, \ldots, \mathrm{d}_{i}^{k}$. Each network band $\mathrm{b}_{i}^{k}$ is a buffer defined around dwelling $i$ such that the network distance from the dwelling to any point in the buffer is no greater than the prespecified value $\mathrm{d}_{i}^{k}$.

In practice, one way of constructing the network bands is as follows:

1. Grow a shortest path tree (SPT) from a given dwelling, $i$;

2. Truncate the SPT branches to include only the nodes within the pre-specified distance, $\mathrm{d}_{i}^{k}$, from the dwelling;

3. Construct a minimum convex hull that covers the truncated SPT. The resulting convex hull is the desired network band $\mathrm{b}_{i}^{k}$.

The above procedure may be implemented using the GISDK script language provided by TransCAD, which is a commercial GIS developed especially for transportation applications. Figure 1(c) shows an example of a network-band generated using a GISDK macro written by us. Compared to the circular neighborhood representation, the network-bands are conceptually more appealing because the bands are less likely to contain natural or physical barriers. Also, while the circular units constructed for a predefined buffer size have identical shapes and sizes, the network-band $\mathrm{b}_{i}^{k}$ corresponding to each dwelling $i$ can vary in size and shape, depending on the density and layout of the surrounding street network. Whereas denser and grid-like streets lead to smaller and more compact network bands, sparse and cul-de-sec 
streets lead to network bands that are larger and more irregular in shape. The degree of variation in the network bands' sizes and shapes is, however, not as great as that of the census units.

\section{Empirical Application}

The three alternative ways described in section 5 for representing neighborhoods have been implemented and empirically applied to the context of residential location choice modeling. The empirical application involves estimating three MSL models, each based on one of the three neighborhood representations. The objectives here are twofold: (1) to examine if, and how, the three configurations suggest different neighborhood effects on residential location choice behavior; and (2) compare the statistical fitness of the models to determine their relative

explanatory power. Below, we describe the sample used for model estimation in section 6.1, the spatial data processing considerations in section 6.2 , the variable specifications in section 6.3 , and the estimation results in section 6.4 .

\section{1. $\quad$ Estimation Sample}

The study region we have chosen to empirically apply the three neighborhood representation methods is the San Francisco Bay Area. The primary data source is the 2000 Bay Area Travel Survey (BATS) that collected, from members of 15,064 households, detailed information on individual and household socio-demographic information, employment-related characteristics and all activity and travel episodes for a two-day period. The dataset also contains the point geocodes of household residences from which the census block, block group and tract in which the residence is situated can be identified. The geocodes also enable us to construct concentric circles and network bands of varying distances around each residence (the sizes of the circles and bands are described later in section 6.2). From the surveyed households, we randomly select 
$50 \%$ of those households living in single-family detached houses. The sub-sampling allows us to avoid the need of differentiating between housing markets. The final sample contains 4791 households.

Following from the MSL structure, the choice alternatives faced by each household are the individual dwellings. In theory, the universal choice set in this case comprises all the singlefamily detached houses in the Bay area. However, not only are data about all such housing units in the area unavailable, but it would be computationally impractical to consider them all. Therefore, we assume that the 4791 residences observed in the sample are a random subset of such housing opportunities, and consider this as the unobserved choice set faced by each individual household. We also assume an identically and independently distributed (IID) structure for the error terms across the alternatives in this universal choice set so that the model can be consistently estimated with only a subset of the choice alternatives (McFadden, 1978). The individual choice set constructed for each of the households in the sample includes the chosen alternative and nine randomly selected non-chosen alternatives.

\subsection{Spatial Data Processing}

Spatial attributes describing the choice alternatives are derived from a number of data sources, as listed in Table 1. These sources provide raw data for such spatial units as TAZ and census blocks and block groups. For our purpose of implementing the alternative neighborhood representations, we need to first construct the hierarchy of census units, circular units, and network bands, respectively. Once the spatial units are created, we then overlay the geographic layer associated with the raw data (the source layer) on to these spatial constructs (the target layer), followed by appropriate disaggregation and aggregation operations to produce the neighborhood measures desired for model estimation. It should be noted that, since our source 
data are already in an aggregate form, the process of disaggregating and aggregating them to the target layer may introduce further information loss or distortion, with the degree of loss or distortion depending on the configurations of the source and target polygons. To avoid such information distortion, one should use source data with the highest spatial resolution.

The construction of the census units is trivial as the Census Bureau provides GIS layers that readily define the census blocks, block groups, and tracts. The construction of the circular units and the network bands, however, requires us to first determine the appropriate radii (in the case of circular units) and band sizes (in the case of network bands). Our selection of radii and band sizes is based on two considerations. First, in order to reduce the magnitude of information distortion due to data disaggregation, the circles and bands should be of sizes no smaller than the census units. The great variation in area size of the census units, however, makes the selection of distance thresholds difficult. For example, the area size of the 1106 census tracts in the Bay Area ranges from 0.05 to $1515.07 \mathrm{~km}^{2}$, which are equivalent to circular areas of radius ranging from 0.13 to $21.97 \mathrm{~km}$. Our second consideration in determining the appropriate sizes for the circular units and network bands is related to the possibility of high correlations between neighborhood variables measured at the different scales. To be sure, such correlation effects also exists among the census units. However, the correlation problem may be worse for the circular units and network bands if the differential increments between the scales are relatively small. Based on these two points of considerations, we choose $0.4 \mathrm{~km}, 1.6 \mathrm{~km}$ and $3.2 \mathrm{~km}$ as the radii and band sizes for the three-scale circular-unit and network-bands representations ${ }^{3}$. The $0.4 \mathrm{~km}$ is slightly greater than the radius of a circle equivalent to the average size of the census blocks

\footnotetext{
${ }^{3}$ The exact measurements of the radii are $0.25,1.0$, and $2.0 \mathrm{mi}$. Their respective metric equivalents of $0.4,1.6$, and $3.2 \mathrm{~km}$ are used in this paper.
} 
(which is $0.27 \mathrm{~km}$ ). It captures the surroundings within what is commonly regarded the average 'walkable' distance. The second level of $1.6 \mathrm{~km}$ radius is comparable to the size of most census block-groups and tracts and perhaps caps the 'walkable' distance. The third level of $3.2 \mathrm{~km}$ radius is selected to detect neighborhood effects that might operate beyond individuals' walking distance. The census units associated with, and the circular units and network bands of the chosen sizes constructed around, each of the 4791 residential locations in the sample are then used to compute the various neighborhood variables described in the following section.

\subsection{Variable Specification}

The following two sets of neighborhood variables are computed for the three sets of spatial units:

(1) Neighborhood socioeconomic and demographic variables

Several variables are computed to test for the presence of segregation along various socioeconomic and demographic dimensions. These include the racial composition variables (percentage of population by race), household type composition variables (percentage of households by type), tenure composition variables (percentage of households owning or renting), household income homogeneity (absolute difference between household income and zonal median income), and household size homogeneity (absolute difference between household size and zonal average household size). The racial, household type and tenure composition variables are further interacted with the corresponding household racial, family type, and tenure attributes.

(2) Neighborhood design variables 
A variety of neighborhood design measures were considered for this analysis.

These include density measures (population density, housing density), land-use composition measures (percentage of coverage by land-use type) and employment density measures (number of employees per person by sector). We also considered a more complex measure of land-use diversity defined by:

$$
M I X_{s}=1-\left(\left|R_{s} / T_{s}-1 / 4\right|+\left|C_{s} / T_{s}-1 / 4\right|+\left|I_{s} / T_{s}-1 / 4\right|+\left|O_{s} / T_{s}-1 / 4\right|\right) / 1.5
$$

where $T_{s}$ is the total area of the unit of analysis $s$; and $R_{s}, C_{s}, I_{s}$ and $O_{s}$ are the acreage of residential, commercial, industrial and other land use types. This land-use mix index takes a value between 0 and 1 , where 1 indicates perfect mixing of land uses and 0 indicates that the land in a particular area is completely dedicated to a single land use (Bhat and Gossen, 2004).

Two additional sets of variables are also considered in our MSL models to capture the effects of regional access, for both commute and non-commute purposes, on the choice of residential location. These variables are:

\section{(1) Commute-related variables}

Based on the residents' work and alternative residential TAZ locations, we extract from the level-of-service data the auto commute times and costs, which are then interacted with individual work status, gender, ethnicity, and income variables.

\section{(2) Regional accessibility}

A residential location's attractiveness depends not only on its immediate surroundings, but also how it relates spatially to the rest of the urban area. This is the motivation for considering regional accessibility measures for shopping, recreational, and employment activities. We compute the accessibility measures 
as $A_{i}^{\text {Shop }}=\left(\sum_{j=1}^{N} R_{j} / d_{i j}\right) / N, A_{i}^{E m p}=\left(\sum_{j=1}^{N} E_{j} / d_{i j}\right) / N$, and $A_{i}^{\operatorname{Rec}}=\left(\sum_{j=1}^{N} V_{j} / d_{i j}\right) / N$

where $A_{i}^{E m p}, A_{i}^{\mathrm{Rec}}$ and $A_{i}^{\text {Shop }}$ denote the shopping, employment and recreational accessibility indices, respectively, for TAZ $i ; R_{j}, E_{j}$ and $V_{j}$ are the number of retail employment, number of basic employment and vacant land acreage in TAZ $i$, respectively; $d_{i j}$ is the distance between zones $i$ and $j$. Due to data constraints, these zonal accessibility measures are used in our analysis as proxy for point-to-region accessibility measures for each observed residence. Large values of the accessibility measures indicate more opportunities for activities in close proximity of that residence, while small values indicate residences that are spatially isolated from such opportunities.

\subsection{Estimation Results}

We arrived at the final specification for each of the three models based on a systematic process of testing and eliminating variables found to be statistically insignificant. The specification was also guided by parsimony and intuitive considerations, and the results from earlier studies. The final specifications are presented in Table 2 (census-unit representation), Table 3 (circular-unit representation) and Table 4 (network-band representation). The results are discussed below by variable group. Overall, the three models are consistent in the signs of the parameter estimates. The final specifications differ in the presence and the absence of certain variables and the spatial level at which the variables are significant. 


\section{Commute-related variables}

The three models are most comparable in terms of the parameter estimates (both in sign and magnitude) associated with commute time. All models reveal that households tend to locate themselves closer to the work locations of the workers in the household. In particular, households locate themselves close to the workplace of the female workers in the household. This gender disparity supports the household responsibility hypothesis (Sermons and Koppelman, 2001). A similar higher responsibility hypothesis may be the underlying cause for the greater commute time effect on part-time workers relative to full-time workers. The racial disparity in commute sensitivity suggests greater spatial job-housing mismatch for nonCaucasians compared to Caucasians. The positive sign associated with the interaction of commute time and income may be a reflection of the willingness of higher income earners to travel further in exchange for better housing quality.

\section{Accessibility-related variables}

The three models also have similar estimates for the sensitivity to employment accessibility. Taken together with the parameter on the interaction term between employment accessibility and income, the results indicate that households earning an annual income greater than $\$ 16000$ (in the census-unit model) or $\$ 12000$ (in the circular-unit model) or $\$ 8000$ (in the network-band model) tend to locate themselves near employment centers even after the direct accessibility to work locations has been accounted for. Single-person households are also found to locate in closer proximity to regional employment opportunities than other types of households. The effect of regional shopping accessibility is different for the models. While the census-unit model suggests that, compared to other household types, couple-only households tend to locate in areas with good access to shopping opportunities, the other two models do not 
suggest any difference in sensitivity to shopping accessibility across household types.

Recreation accessibility measures were introduced into the utility function during the estimation process, but were not found to impact residential choice.

\section{Residential segregation effects}

A consistent finding in all models is the evidence of residential segregation across a number of dimensions. As indicated by the magnitude of the parameter estimates, AfricanAmericans are the most segregated group, while Hispanics and Asians are segregated to a lesser degree - this finding is in agreement with the national demographic trend found in Iceland et al. (2002). The results essentially indicate that African-Americans and Hispanics are more likely to integrate with other minority groups compared to Caucasian and Asians. It is also interesting that, despite the common impression of strong Black-White segregation, the coefficient associated with the share of Caucasian population interacted with Caucasian household is relatively smaller than the respective coefficient associated with the share of AfricanAmerican/Asian/Hispanic population interacted with African-American/Asian/ Hispanic household. This perhaps indicates that the Caucasians in the Bay area have a relatively high tolerance for the presence of the other population groups as a whole in their neighborhoods.

Evidence of strong racial segregation is a common finding in past studies of residential location choice. What past studies have not been able to reveal is the differential spatial extents of the racial clustering behavior. Our estimation results show that the size of racial clusters does vary for different racial groups and that different neighborhood definitions suggest different cluster sizes. In Tables 3 and 4, almost all the racial clustering variables are significant at, and only at, the $0.4 \mathrm{~km}$ direct/network distance level, with the exception being the aggregation of the 'other' ethnic population with African-American households. This suggests that racial clusters 
are generally of $0.4 \mathrm{~km}$ in radius. The census-unit model in Table 2 , however, tells a different story. The aggregation among Caucasians and among African-Americans is prominent in census blocks only; whereas the aggregation among Asians and among Hispanics is found in both census blocks and block-groups. Also, the integration of African-Americans and of Hispanics with the other minority groups is found only at the tract level. This difference in spatial scales of racial segregation between the two models is perhaps a result of the MAUP, the variation in the sizes of census units, or other factors that require further research to uncover.

The household structure-related segregation effects suggest that a household tends to locate in an area with a high proportion of other households with a similar household structure and household size as their own. Table 2 suggests the presence of clustering among couple-only and nuclear-family households at the census block-group level, and clustering among singleperson and couple-only households at the census tract level. Tables 3 and 4 both show that the cluster size of single-person households $(1.6 \mathrm{~km})$ is higher than that of the other household types $(0.4 \mathrm{~km})$. In addition to segregation by race and household structure, households are found to locate near other households of similar income level, household size, and residential tenure status. Again, the observed inconsistency between the three models regarding the clustering size of households along various demographic and socio-economic dimensions calls for further research.

\section{Neighborhood design factors}

The consistency of the neighborhood design parameters among the three models is very mixed. Density and density interacted with nuclear-family households are significant in all three models, but show different spatial extents of influence. The census-unit model implies that households generally locate in census tracts of high population density, but nuclear-families are 
less likely to location in census block-groups of high density. The circular-unit and networkband models indicate that high population density within close proximity $(0.4 \mathrm{~km}$ in terms of air or network distance) of households' residence generally has a positive influence on households' residential location choice. However, population density has a negative influence on nuclearfamily households, and the extent of this influence is within a $1.6 \mathrm{~km}$ radius of their residence (the circular-unit model) or $3.2 \mathrm{~km}$ network distance from their residence (the network-band model). In the census-unit model, density is also found to have an additional positive effect on African-Americans and a negative effect on high-income households. In the network-band model, density also has a negative effect on high-income households (annual income above \$114 000).

Of the several land-use composition variables and their interaction terms with household characteristics, only the share of the commercial land-use variable and the share of commercial land-use interacted with household income variable are significant in both census-unit and circular-unit model specifications. Taken together, the parameters suggest that the attractiveness of local access (within the same census block-group, or within the $1.6 \mathrm{~km}$ radius neighborhood) to stores diminishes as household income increases. In addition, as suggested by the census-unit model but not the circular-unit model, couple-only households are less likely to location in census block-groups with high commercial land-use than other types of households. The censusunit model also indicates different effects of residential land-use at two spatial scales on singleonly households. On the other hand, the network-band model suggests that, compared to lowerincome households, high income households are more likely to locate themselves in residentialoriented areas (within $1.6 \mathrm{~km}$ of the residence). Also, couple-only households tend to locate themselves in areas with less open space then other types of households. 
Of the employment density variables tested, only the service employment density variable has an influence on residential choice decisions. The census-unit model indicates that, on the one hand, nuclear-family, couple-only and single-only households are more likely to locate in census tracts with high service employment density, with the degree of likelihood being highest for nuclear-families and lowest for single-only households; but on the other hand, households other than these three types are less likely to locate in such tracts. The effects of service employment density, however, are not evident in the circular-unit model nor the networkband model.

It is surprising that the land-use mix parameter, either by itself or through interaction with the various household characteristics, does not appear to be a significant factor in the census-unit model. This suggests that, after the access to particular types of land-use (commercial) or amenity (service) is accounted for, mixed land-use does not have influence on residential location choice behavior. With the network-band model, however, we find evidence supporting the hypothesis that households with no car are more likely to reside in mixed land-use environment. The circular-unit model also suggests effects of land-use mix, measured within 1.6 $\mathrm{km}$ network distance, on residential location choice. Measured within a $3.2 \mathrm{~km}$ radius around the residences, heterogeneous land-use composition has a positive effect on households with none or one car, and a negative effect on households with young children. These effects appear to be intuitive.

\section{Measures of fit}

Since the number of variables present in the final specifications is different between the census-unit model and the circular-unit model, the log-likelihood ratios are not directly comparable. Instead, we compare the goodness-of-fit of the two models using the adjusted 
likelihood ratio (ALR). The values of the ALR for the census-unit, circular-unit, and network band models are $0.183,0.183,0.184$, respectively. That is, statistically speaking, the networkband model is found to be superior to the other two models. The differences in model goodnessof-fits are, however, quite small and not statistically significantly different based on non-nested likelihood ratio tests (see Ben-Akiva and Lerman, 1985, for a discussion of non-nested likelihood ratio tests).

\section{Summary and Conclusions}

The 'neighborhood' is a key concept in urban study. Its attributes can be observed and accurately measured only after a location has been specified and a space of relevance been demarcated. In this study, we investigate the spatial definition problem of neighborhood in the context of residential location choice analysis. From past research efforts aimed at conceptualizing the nature of neighborhood, we learn that neighborhood is intrinsically hierarchical and is continuously shaped by the infrastructure and the many ecological and social processes that take place in the urban environment. The hierarchical organization and the spatial boundaries of neighborhood are very much domain dependent. In certain contexts they can be described by objectively recognizable spatial delineations while, in other situations, they are constructed by individuals' perception. This dynamic nature of neighborhood renders the popular grouped alternatives modeling approach methodologically flawed. By not appropriately considering neighborhood attributes over the area that really matters to the decision makers, these past modeling efforts produce biased parameter estimates that lead to erroneous interpretations and ineffective policies.

We contend that, with the increasing availability of micro-level spatial data and the proliferation of GIS, researchers should re-examine the conventional practice and consider the 
more general, and behaviorally more realistic, MSL modeling approach. The MSL model serves as a useful tool for uncovering the appropriate spatial structure to best represent neighborhood for a given study context. Our earlier work (Guo and Bhat, 2004) showed that, at least in the context of residential location choice analysis, the hierarchical nature of the MSL model outperforms the single-level model both conceptually and statistically. The MSL model is especially valuable in its ability to allow the spatial scale of relevance for each variable to be determined endogenously.

In this paper, we explore different conceptualizations of neighborhoods and describe three alternative ways for constructing operational units to represent neighborhoods. In particular, we examine the possibility of using the census units to represent the hierarchical 'fixed neighborhood' definition, and circular units and network bands around housing units to represent the hierarchical 'sliding neighborhood' definition. Each of these three neighborhood representations has its conceptual merits and drawbacks. The fact that the boundaries of census units often follow the street network makes the units a good candidate for studying the neighborhood factors whose influence are perceived to differ from one street block to the other. However, the same quality also makes the census unit unsuitable for studying other types of neighborhood processes. Another major drawback is that the census units vary greatly in size and shape, rendering it difficult to interpret the associated parameters. One the same note, the distance-based units (circular units and network bands) provide much more tangible indication of the spatial extents of the neighborhood factors' influence. Moreover, since the network bands are constructed based on the street network, they have the desirable quality of including major natural/physical barriers in their boundary definition. 
Our empirical application of the three neighborhood representation methods in studying households' residential location choices showed that the network band representation is statistically, but not significantly, superior to the other two representations. A number of additional conclusions can be drawn from the empirical results. First, the three models are generally consistent in the signs and magnitudes of the parameter estimates relating to the commute-related and the regional accessibility variables. For the other variables considered in the analysis, the models differ in the variables that are significant and the spatial scale at which these variables are significant. Second, for parameters that are found to be significant, they tend to have the same sign but their respective values can differ up to $300 \%$. Third, all three models suggest that the social-economic and demographic composition variables have significantly smaller spatial extent of influence than the land-use variables. The aforementioned findings can perhaps explain why previous residential choice models utilizing the GAC approach sometimes fail to provide empirical evidence for certain intuitive hypotheses about the impact of neighborhood characteristics on residential utility.

The current study has demonstrated the feasibility, and the potential benefits, of breaking away from utilizing administrative zones in residential location choice analysis, as well as other activity-based analyses that involve neighborhood variables. Yet, it does not necessarily answer the question of what operational units are most suitable for analyzing neighborhood variables. In fact, this study represents only the beginning of an inquiry into that question. Future research along this line of inquiry may include the following: (1) empirically applying and comparing the alternative spatial representations based on disaggregate data (as opposed to, for example, land use data at the TAZ level) to more accurately assess their empirical explanatory power; (2) devising alternative hierarchical representations of neighborhoods to incorporate both of (or the 
merits of both) the fixed- and sliding-neighborhood concepts; (3) examining the appropriate scales of analysis to successfully identify the effects of neighborhood variables while avoiding the effects of multi-colinearity; (4) designing surveys to collect data that will help identify respondents' perceived neighborhood boundaries.

\section{Acknowledgement}

We would like to thank Professor Harvey Miller for his suggestion on defining neighborhoods based on network distance and an anonymous individual for constructive comments on an earlier version of the paper. 


\section{Reference}

Ben-Akiva, M., Lerman, S. R., 1985. Discrete Choice Analysis: Theory and Application to Travel Demand. MIT Press, Cambridge, Massachusetts.

Bhat, C.R., Gossen, R., 2004. A mixed multinomial logit model analysis of weekend recreational episode type choice. Transportation Research Part B 38(9), 767-787.

Bhat, C.R. and Guo, J.Y., 2005. A comprehensive analysis of built environment characteristics on household residential choice and auto ownership levels. Technical paper, Department of Civil Engineering, The University of Texas at Austin, July 2005.

Boarnet, M .G., Sarmiento, S., 1998. Can land-use policy really affect travel behavior? A study of the link between non-work travel and land-use characteristics. Urban Studies 35(7), 1155-1169.

Brodsky, A., O’Campo, P., Aronson, R., 1999. PSOC in community context: multilevel correlates of a measure of psychological sense of community in low income, urban neighborhoods. Journal of Community Psychology 27, 659-680.

Chattopadhyay, S., 2000. The Effectiveness of McFadden's Nested Logit Model in Valuing Amenity Improvement, Regional Science and Urban Economics 30, 23-43.

Coulton, C.J., Korbin, J., Chan, T., Su, M., 2001. Mapping residents’ perceptions of neighborhood boundaries: A methodological note. American Journal of Community Psychology 29(2), 371-383.

Deng, Y., Ross, S.L., Wachter, S.M., 2003. Racial Differences in Homeownership: The Effect of Residential Location, Regional Science and Urban Economics 33, 517-556.

Dietz, R.D., 2002. The estimation of neighborhood effects in the social sciences: An 
interdisciplinary approach. Social Science Research 31, 539-575.

Dubin, R.A., 1992. Spatial Autocorrelation and Neighborhood Quality. Regional Science and Urban Economics 22, 433-452.

Duncan, T.E., Duncan, S.C., Okut, H., Strycker, L.A., Hix-Small, H., 2003. A multilevel contextual model of neighborhood collective efficacy. American Journal of Community Psychology 32(3/4), 245-252.

Ewing, R., Cervero, R., 2001. Travel and the built environment - synthesis. Transportation Research Record 1780, 87-114.

Fotheringham, A.S., Wong, D.W.S., 1991. The modifiable areal unit problem in multivariate statistical analysis. Environment and Planning A 23, 1025-1044.

Galster, G.C., 2001. On the nature of neighborhood. Urban Studies 38(12), 2111-2124.

Gabriel, S.A., Rosenthal, S.S., 1989. Household Location and Race: Estimates of a Multinomial Logit Model, The Review of Economics and Statistics 17 (2), 240-249.

Goldstein, H., 1995. Multilevel Statistical Models. Edward Arnold, London.

Grannis, R., 2003. Islands in the city: Social networks and street networks. Working paper, Department of Sociology, University of California, Los Angeles.

Grannis, R., 1998. The importance of trivial streets: Residential streets and residential segregation. American Journal of Sociology 103(6), 1530-1564.

Guest, A.M., Lee, B.A., 1984. How urbanites define their neighborhoods. Population and Environment 7(1), 32-56.

Guo, J.Y., Bhat, C.R., 2004. Modifiable areal units: a problem or a matter of perception? Transportation Research Record, forthcoming. 
Horton, F.E., Reynolds, D.R., 1971. Effects of urban spatial structure on individual behavior. Economic Geography 47(1), 36-48.

Hox, J.J., Kreft, I.G., 1994. Multilevel analysis methods, Sociological Methods and Research, 22, 283-299.

Hunt, J.D., McMillan, J.D.P., Abraham, J.E., 1994. Stated Preference Investigation of Influences on Attractiveness of Residential Locations. Transportation Research Record 1466, 79-87.

Iceland, J., Weinberg, D.H., Steinmetz, E., 2002. Racial and Ethnic Residential Segregation in the United States: 1980-2000. U.S. Census Bureau, Census Special Report, CENSR-3, US Government Printing Office, Washington, DC.

Kitamura, R., Mokhtarian P.L., Laidet, L., 1997. A micro-analysis of land use and travel in five neighborhoods in the San Francisco Bay Area. Transportation 24(2), 125-158.

Lee, B.A., Campbell, K.E., Miller, O., 1991. Racial differences in urban neighboring. Sociological Forum 9(3), 525-550.

Levine, J., 1998. Rethinking Accessibility and Jobs-Housing Balance, Journal of American Planning Association 64(2), 133-149.

Lerman, S.R., 1976. Location, Housing, Automobile Ownership and Mode to Work: A Joint Choice Model. Transportation Research Record 610, 6-11.

Lund, H., 2003. Testing the claims of New Urbanism. APA Journal 69(4), 414-429.

McFadden, D., 1978. Modeling the Choice of Residential Location. In: Karlqvist, A. et al. (Eds), Spatial Interaction Theory and Planning Models. Amsterdam: North Holland Publishers.

Nechyba, T.J., Strauss, R.P., 1998. Community Choice and Local Public Services: A Discrete Choice Approach, Regional Science and Urban Economics 28, 51-73. 
O’Campo, P., 2003. Invited commentary: Advancing theory and methods for multilevel models of residential neighborhoods and health. American Journal of Epidemiology 157(1), 9-13. Openshaw, S., 1984. Concepts and Techniques in Modern Geography: Number 38 - The Modifiable Areal Unit Problem. Norwick: Geo Books.

Orford, S., 2002. Valuing locational externalities: A GIS and multilevel modeling approach. Environment and Planning B: Planning and Design 29, 105-127.

Park, R., 1916. Suggestions for the Investigations of Human Behavior in the Urban Environment. American Journal of Sociology 20(5), 577-612.

Quigley, J.M., 1985. Consumer Choice of Dwelling, Neighborhood and Public Services. Regional Science and Urban Economics 15, 41-63.

Rapaport, C., 1997. Housing Demand and Community Choice: An Empirical Analysis, Journal of Urban Economics 42, 243-260.

Sampson, R.J., Morenoff, J.D., Gannon-Rowley, T., 2002. Assessing 'neighborhood effects': Social processes and new directions in research. Annual Reviews in Sociology 28, 443478.

Sermons, M.W., Koppelman, F.S., 2001. Representing the differences between female and male commute behavior in residential location choice models. Journal of Transport Geography 9(2), 101-110.

Shinn, M., Toohey, S.M., 2003. Community contexts of human welfare. Annual Reviews in Psychology 54, 427-459.

Suttles, G.D., 1972. The Social Construction of Communities. Chicago: University of Chicago Press. 
Waddell, P., 1996. Accessibility and Residential Location: The Interaction of Workplace, Residential Mobility, Tenure, and Location Choices, presented at the Lincoln Land Institute TRED Conference. [http://www.odot.state.or.us/tddtpan/modeling.html]

Waddell, P., 1993. Exogenous workplace choice in residential location models: Is the assumption valid?. Geographical Analysis 25, 65-82. 


\section{LIST OF TABLES}

TABLE 1 Spatial variables considered in the residential choice models

TABLE 2 Estimation results for the census-unit neighborhood model

TABLE 3 Estimation result for the circular-unit neighborhood model

TABLE 4 Estimation result for the network-band neighborhood model

\section{LIST OF FIGURES}

FIGURE 1 Alternative ways of representing perceived neighborhood 
TABLE 1. Spatial variables considered in the residential choice models

\begin{tabular}{|c|c|c|}
\hline Data source & $\begin{array}{l}\text { Spatial level at which data } \\
\text { is available }\end{array}$ & Variables considered \\
\hline $\begin{array}{l}\text { Bay Area Metropolitan } \\
\text { Transportation } \\
\text { Commission }\end{array}$ & Transport analysis zone & $\begin{array}{l}\text { - Number of employment by sector (retail, } \\
\text { wholesale, service, manufacturing, agriculture, and } \\
\text { other) } \\
\text { - Land-use acreage by purpose (residential, office, } \\
\text { retail, and vacant) }\end{array}$ \\
\hline $\begin{array}{l}\text { Bay Area Metropolitan } \\
\text { Transportation } \\
\text { Commission }\end{array}$ & Transport analysis zone & $\begin{array}{l}\text { Inter-zonal } \\
\text { - Distances } \\
\text { - Peak and off-peak travel times and costs by travel } \\
\text { mode (car, shared ride, transit mode by both walk } \\
\text { access, and transit mode by drive access) }\end{array}$ \\
\hline \multirow[t]{2}{*}{$\begin{array}{l}\text { Census } 2000 \text { population } \\
\text { and housing data } \\
\text { summary file } 1 \text { (SF1) }\end{array}$} & Census block & $\begin{array}{l}\text { - Number of households } \\
\text { - Population } \\
\text { - Land/water area } \\
\text { - Number of people by ethnicity (non-Hispanic } \\
\text { Caucasian, African American, Asian, Hispanic, } \\
\text { and other) }\end{array}$ \\
\hline & Census block-group & $\begin{array}{l}\text { - Median household income } \\
\text { - Average household size } \\
\text { - Number of housing units by size (single-family } \\
\text { detached, apartments, etc) } \\
\text { - Median housing value } \\
\text { - Number of households by income quartiles }\end{array}$ \\
\hline
\end{tabular}


Table 2. Estimation results for the census-unit neighborhood model

\begin{tabular}{|c|c|c|c|c|c|c|c|c|}
\hline \multicolumn{3}{|c|}{ Variables } & \multicolumn{6}{|c|}{ Multi-scale } \\
\hline Location attribute & $(\mathrm{x}$ & Household attribute & \multicolumn{3}{|c|}{ Param. } & \multicolumn{3}{|c|}{ t-stat. } \\
\hline \multicolumn{3}{|l|}{ Commute-related variables } & & \multirow{2}{*}{\multicolumn{3}{|c|}{-9.55}} \\
\hline Commute Time & $\mathrm{x}$ & Full-time male workers & \multicolumn{2}{|c|}{-0.043} & & & & \\
\hline Commute Time & $\mathrm{x}$ & Full-time female workers & \multicolumn{3}{|c|}{-0.056} & \multicolumn{3}{|c|}{-11.88} \\
\hline Commute Time & $\mathrm{x}$ & Part-time male workers & \multicolumn{3}{|c|}{-0.073} & \multicolumn{3}{|c|}{-8.57} \\
\hline Commute Time & $\mathrm{x}$ & Part-time female workers & \multicolumn{3}{|c|}{-0.088} & \multicolumn{3}{|c|}{-15.26} \\
\hline Commute Time & $\mathrm{x}$ & Caucasian household & \multicolumn{3}{|c|}{-0.010} & \multicolumn{3}{|c|}{-3.21} \\
\hline Commute Time & $\mathrm{x}$ & household income (in $\$ 100000$ ) & \multicolumn{3}{|c|}{0.006} & \multicolumn{3}{|c|}{1.89} \\
\hline \multicolumn{3}{|l|}{ Accessibility-related variables } & & \\
\hline Employment Accessibility & & & & -0.016 & & \multicolumn{3}{|c|}{-6.76} \\
\hline Employment Accessibility & $\mathrm{x}$ & Household income (in $\$ 1000$ ) & & 0.001 & & & 6.10 & \\
\hline Employment Accessibility & $\mathrm{x}$ & Single-person household & & 0.009 & & & 4.25 & \\
\hline Shopping Accessibility & $\mathrm{x}$ & Couple only household & & 0.003 & & & 1.91 & \\
\hline & & & Blo & & Block & oup & Tre & \\
\hline & & & Param. & t-stat. & Param. & t-stat. & Param. & t-stat. \\
\hline Residential segregation effects & & & & & & & & \\
\hline Share of Caucasian population & $\mathrm{x}$ & Caucasian household & 0.667 & 6.72 & & & & \\
\hline Share of African population & $\mathrm{x}$ & African household & 9.426 & 8.97 & & & & \\
\hline Share of Asian population & $\mathrm{x}$ & Asian household & 2.887 & 3.92 & 2.348 & 2.87 & & \\
\hline Share of Hispanic population & $\mathrm{x}$ & Hispanic household & 1.737 & 1.66 & 3.467 & 2.69 & & \\
\hline Share of other ethnic population & $\mathrm{x}$ & African household & & & & & 38.606 & 2.98 \\
\hline Share of other ethnic population & $\mathrm{x}$ & Hispanic household & & & & & 32.074 & 3.14 \\
\hline Share of single-person household & $\mathrm{x}$ & Single-person household & & & & & 0.962 & 2.10 \\
\hline Share of couple-only household & $\mathrm{x}$ & Couple-only household & & & 0.987 & 2.39 & 1.286 & 2.14 \\
\hline Share of nuclear-family household & $\mathrm{x}$ & Nuclear-family household & & & 1.136 & 3.23 & & \\
\hline $\begin{array}{l}\text { Absolute diff. between zonal media } \\
(\$ 1000)\end{array}$ & an incon & me and household income & & & -0.010 & -11.45 & & \\
\hline $\begin{array}{l}\text { Absolute diff. between zonal avera } \\
\text { size }\end{array}$ & ge hous & isehold size and household & & & -0.185 & -4.23 & & \\
\hline Share of owner-occupied housing & $\mathrm{x}$ & Own house & & & & & 0.234 & 1.67 \\
\hline Zonal Median house value $(\$ 1000)$ & $\mathrm{x}$ & Inverse of total income & & & -0.020 & -3.56 & & \\
\hline Neighbourhood design factors & & & & & & & & \\
\hline Density (per $10000 \mathrm{mi}^{2}$ ) & & & & & & & 0.227 & 3.70 \\
\hline Density (per $10000 \mathrm{mi}^{2}$ ) & $\mathrm{x}$ & African American household & 0.182 & 2.00 & & & & \\
\hline Density (per $10000 \mathrm{mi}^{2}$ ) & $\mathrm{x}$ & Nuclear-family household & & & -0.161 & -2.06 & & \\
\hline Density (per $10000 \mathrm{mi}^{2}$ ) & $\mathrm{x}$ & Household income $>\$ 75,000$ & & & & & -0.240 & -3.28 \\
\hline Share of commercial land-use & & & & & 1.283 & 3.59 & & \\
\hline Share of commercial land-use & $\mathrm{x}$ & Couple only household & & & -0.712 & -1.92 & & \\
\hline Share of commercial land-use & $\mathrm{x}$ & Household income (in $\$ 1000$ ) & & & -0.012 & -3.12 & & \\
\hline Share of residential land-use & $\mathrm{x}$ & Single-person household & 1.202 & 2.08 & -1.118 & -1.88 & & \\
\hline No. of service employment (per $10 \mathrm{p}$ & eoople) & & & & & & -0.055 & -2.30 \\
\hline $\begin{array}{l}\text { No. of service employment (per } 10 \\
\text { people) }\end{array}$ & & x Single-person household & & & & & 0.058 & 2.40 \\
\hline $\begin{array}{l}\text { No. of service employment (per } 10 \\
\text { people) }\end{array}$ & & x Couple only household & & & & & 0.059 & 2.28 \\
\hline $\begin{array}{l}\text { No. of service employment (per } 10 \\
\text { people) }\end{array}$ & & x Nuclear family household & & & & & 0.080 & 2.90 \\
\hline Number of observations & & & & &  & & & \\
\hline Log-likelihood at convergence & & & & & -897 & .83 & & \\
\hline
\end{tabular}


Table 3. Estimation result for the circular-unit neighborhood model

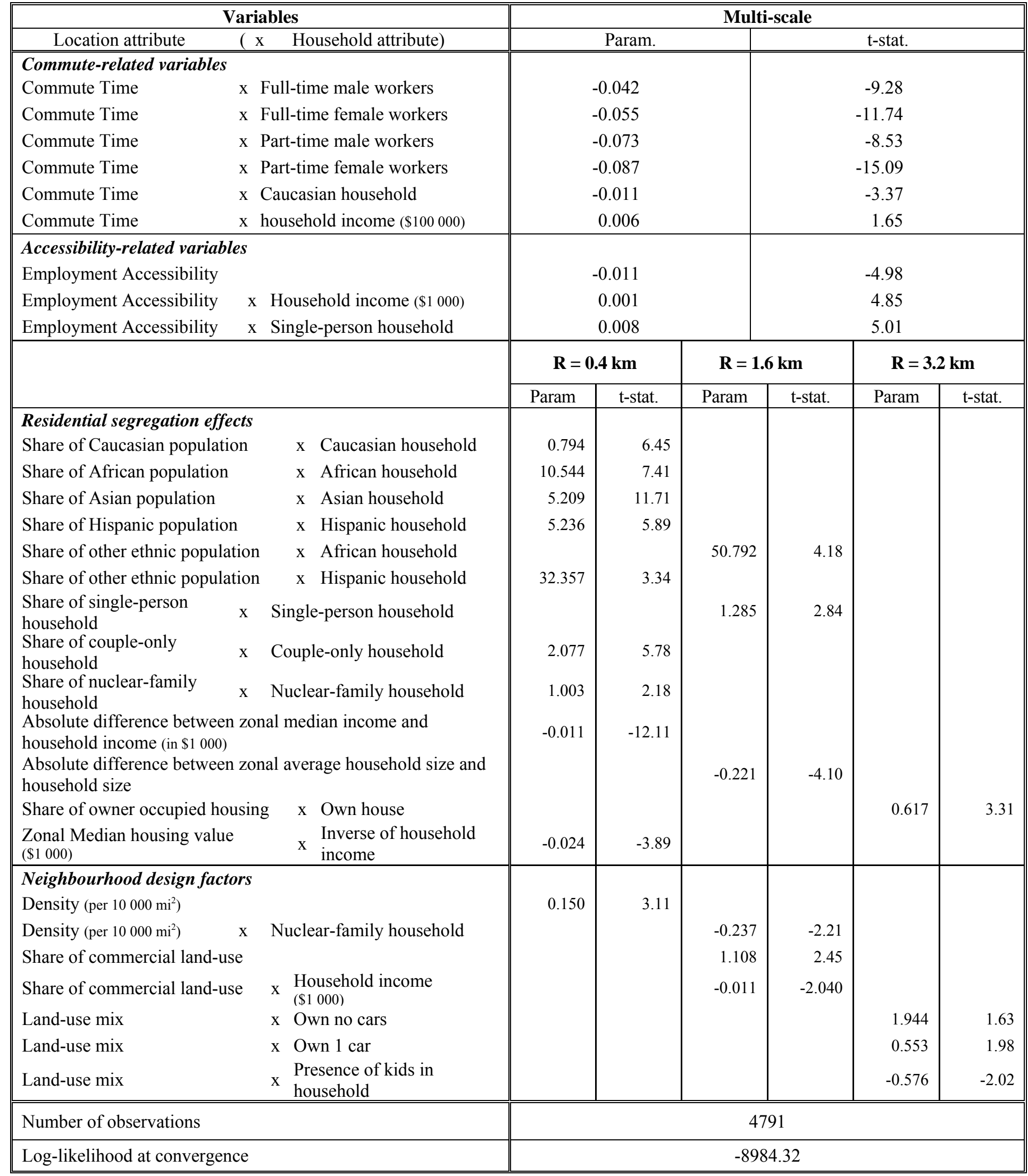


Table 4. Estimation result for the network-band neighborhood model

\begin{tabular}{|c|c|c|c|c|c|c|c|c|}
\hline \multicolumn{3}{|c|}{ Variables } & \multicolumn{6}{|c|}{ Multi-scale } \\
\hline Location attribute & $(\mathrm{x}$ & Household attribute) & \multicolumn{3}{|c|}{ Param. } & \multicolumn{3}{|c|}{ t-stat. } \\
\hline \multicolumn{9}{|l|}{ Commute-related variables } \\
\hline Commute Time & $\mathrm{x} \mathrm{Fu}$ & all-time male workers & \multicolumn{3}{|c|}{-0.042} & \multicolumn{3}{|c|}{-9.49} \\
\hline Commute Time & $\mathrm{x} \mathrm{Fu}$ & all-time female workers & \multicolumn{3}{|c|}{-0.055} & \multicolumn{3}{|c|}{-11.93} \\
\hline Commute Time & $\mathrm{x} \mathrm{Pa}$ & art-time male workers & \multicolumn{3}{|c|}{-0.072} & \multicolumn{3}{|c|}{-8.63} \\
\hline Commute Time & $\mathrm{x} \mathrm{Pa}$ & art-time female workers & \multicolumn{3}{|c|}{-0.087} & \multicolumn{3}{|c|}{-15.13} \\
\hline Commute Time & $\mathrm{x} \mathrm{Ca}$ & aucasian household & \multicolumn{3}{|c|}{-0.011} & \multicolumn{3}{|c|}{-3.31} \\
\hline Commute Time & $\mathrm{x}$ ho & ousehold income $(\$ 100000)$ & \multicolumn{3}{|c|}{0.006} & \multicolumn{3}{|c|}{1.87} \\
\hline \multicolumn{9}{|l|}{ Accessibility-related variables } \\
\hline Employment Accessibility & & & \multicolumn{3}{|c|}{-0.009} & \multicolumn{3}{|c|}{-4.47} \\
\hline Employment Accessibility & $\mathrm{xH}$ & Household income (\$1 000) & \multicolumn{3}{|c|}{0.001} & \multicolumn{3}{|c|}{4.17} \\
\hline \multicolumn{3}{|c|}{ Employment Accessibility $\quad \mathrm{x}$ Single-person household } & \multicolumn{3}{|c|}{0.008} & \multicolumn{3}{|c|}{4.93} \\
\hline & & & $\mathbf{R}=\mathbf{0}$ & & $\mathbf{R}=\mathbf{1}$ & & $\mathbf{R}=\mathbf{3}$. & \\
\hline & & & Param & t-stat. & Param & t-stat. & Param & t-stat. \\
\hline Residential segregation effe & & & & & & & & \\
\hline Share of Caucasian populatic & & x Caucasian household & 0.769 & 6.41 & & & & \\
\hline Share of African population & & $\mathrm{x}$ African household & 10.266 & 7.41 & & & & \\
\hline Share of Asian population & & x Asian household & 5.151 & 11.71 & & & & \\
\hline Share of Hispanic population & & x Hispanic household & 5.024 & 5.76 & & & & \\
\hline Share of other ethnic populat & ion & $\mathrm{x}$ African household & & & 49.832 & 4.12 & & \\
\hline Share of other ethnic populat & ion & x Hispanic household & 18.760 & 2.70 & & & & \\
\hline $\begin{array}{l}\text { Share of single-person } \\
\text { household }\end{array}$ & x S & Single-person household & & & 1.491 & 3.17 & & \\
\hline $\begin{array}{l}\text { Share of couple-only } \\
\text { household }\end{array}$ & $\mathrm{x} \quad \mathrm{C}$ & Couple-only household & 1.707 & 5.15 & & & & \\
\hline $\begin{array}{l}\text { Share of nuclear-family } \\
\text { household }\end{array}$ & $\mathrm{x} \quad \mathrm{N}$ & Nuclear-family household & 1.110 & 2.69 & & & & \\
\hline $\begin{array}{l}\text { Absolute difference between } \\
\text { household income (in } \$ 1000 \text { ) }\end{array}$ & zonal & 1 median income and & -0.010 & -11.84 & & & & \\
\hline $\begin{array}{l}\text { Absolute difference between } \\
\text { household size }\end{array}$ & zonal & 1 average household size and & -0.184 & -4.04 & & & & \\
\hline Share of owner occupied hou & sing & x Own house & & & & & 0.485 & 3.01 \\
\hline $\begin{array}{l}\text { Zonal Median housing value } \\
(\$ 1000)\end{array}$ & & $\begin{array}{l}\text { x Inverse of household } \\
\text { income }\end{array}$ & -0.028 & -3.91 & & & & \\
\hline Neighbourhood design factc & & & & & & & & \\
\hline Density (per $10000 \mathrm{mi}^{2}$ ) & & & 0.151 & 2.87 & & & & \\
\hline Density (per $10000 \mathrm{mi}^{2}$ ) & $\mathrm{x} \quad \mathrm{N}$ & Nuclear-family household & & & & & -0.274 & -2.46 \\
\hline Density (per $10000 \mathrm{mi}^{2}$ ) & $\begin{array}{ll}\mathrm{x} & \mathrm{H}\end{array}$ & High income households & -0.110 & -1.64 & & & & \\
\hline Share of residential land-use & & & & & & & -0.360 & -2.41 \\
\hline Share of residential land-use & $\mathrm{x}$ & x $\begin{array}{l}\text { Household income } \\
(\$ 1000)\end{array}$ & & & 0.003 & 2.00 & & \\
\hline Share of open space & $\mathrm{x}$ & x Couple-only households & & & & & -0.259 & -2.28 \\
\hline Land-use mix & $\mathrm{x}$ & $\mathrm{x}$ Own no cars & & & 2.009 & 2.16 & & \\
\hline Number of observations & & & & & & & & \\
\hline Log-likelihood at convergen & & & & & & & & \\
\hline
\end{tabular}


Figure 1. Alternative ways of representing perceived neighborhood

(a) Fixed neighborhood representation based on census units
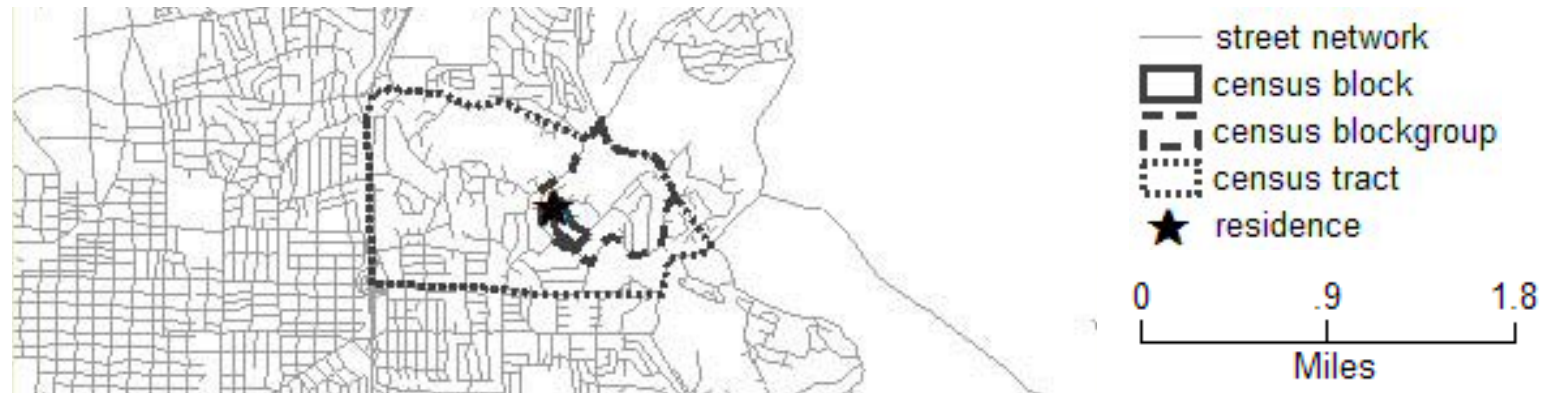

(b) Sliding neighborhood representation based on circular-units


(c) Sliding neighborhood representation based on network bands

- street network network band $(\mathrm{d}=0.25 \mathrm{mi})$
network band ( $\mathrm{d}=1 \mathrm{mi})$ i...... network band (d=2mi)
$\star$ residence



